\title{
Effects of Different Selenium Concentrations on the Photosynthetic Pigment Content in Solanum alatum
}

\author{
Kewen Huang ${ }^{1, a}$, Huashan Lian ${ }^{2, b}$, Ming'an Liao ${ }^{1, c}$ and Lijin Lin ${ }^{3, d *}$ \\ ${ }^{1}$ College of Horticulture, Sichuan Agricultural University, Chengdu, Sichuan, China \\ ${ }^{2}$ Department of Landscape Gardening, Chendu Agricultural College, Chengdu, Sichuan, China \\ ${ }^{3}$ Institute of Pomology and Olericulture, Sichuan Agricultural University, Chengdu, Sichuan, China \\ a263733029@qq.com, b49939450@qq.com, Iman@sicau.edu.cn, dllj800924@qq.com \\ ${ }^{*}$ Corresponding author. Kewen Huang and Huashan Lian contributed equally to this work.
}

\begin{abstract}
Keywords: Solanum alatum; Selenium; Photosynthetic pigment
Abstract: A pot experiment was carried out to study effects of different selenium concentrations ( 0 , $5,10,25,50,75,100 \mathrm{mg} / \mathrm{kg}$ ) on the photosynthetic pigment content in Solanum alatum. The results showed that all concentrations of selenium inhibited the chlorophyll $a$, chlorophyll $b$ and carotenoid contents in $S$. alatum. The selenium concentrations order of $S$. alatum chlorophyll $a$ and chlorophyll $b$ contents from large to small were both ranked: $0,10,5,25,50,75$ and $100 \mathrm{mg} / \mathrm{kg}$. Compared with the $0 \mathrm{mg} / \mathrm{kg}$, only the selenium concentration of $10 \mathrm{mg} / \mathrm{kg}$ had little effect on the photosynthetic pigment contents of $S$. alatum. These results indicated that high concentrations of selenium stress have significant inhibitory the effects on the photosynthetic pigment contents in S. alatum, which were not conducive to the growth of $S$. alatum, but $S$. alatum could grow normally at a selenium concentration of $10 \mathrm{mg} / \mathrm{kg}$.
\end{abstract}

\section{Introduction}

Selenium (Se) is an essential trace element in human life activities and plays a key role in immune regulation, antioxidant defense system and thyroid hormone metabolism [1]. Deficiency of Se can cause the lipid peroxidase reaction to increase and metabolic disorders, easily causing damage to the myocardial arterioles and capillaries [2]. However, Se is a typical dual-function element. When the Se content is too high, it can cause poisoning to the human body and have a significant impact on the skin, nerves, and respiratory system [3]. Therefore, it is of great significance to find a safe and efficient source of Se. Studies have found that organic Se was safer and more easily absorbed by humans and animals than inorganic Se [4]. As a producer in the ecosystem, plants play an important role in the chemical cycle of Se, and are the main carriers for converting inorganic Se into organic Se. Rosenfeld and Beath divide plants into three types: primary Se accumulator, secondary Se accumulator and Non-Se accumulator based on their ability to accumulate Se [5]. In order to reduce the diseases caused by low Se and to repair Se contaminated soil, it is important to screen more Se-resistant plants. The study found that low Se can promote the photosynthesis of plant leaves, but high concentrations of Se have a significant inhibitory effect on chlorophyll and carotenoids content of plants [6-7]. Photosynthesis is the basis of plant growth and development, which determines whether plants can grow normally. Solanum alatum is a variant of Solanum with a long history of food and medicinal use, which has a high nutritional content and high medicinal value [8]. Zeng et al. studied the effects of cadmium stress on physiological and biochemical characteristics of $S$. alatum seedlings and found that cadmium stress increased the content of malondialdehyde while inhibiting the root length and chlorophyll contents [9]. However, the effects of Se on photosynthesis of $S$. alatum have not yet been reported. Therefore, in order to screen more Se sources, $S$. alatum was used as the material to study the effects of different concentrations of Se on $S$. alatum chlorophyll and carotenoid contents.

\section{Materials and Methods}

Materials collection. The seeds of S. alatum were collected from the farmland of Chengdu Campus 
of Sichuan Agricultural University. In March 2018, the S. alatum seeds were sown in $25^{\circ} \mathrm{C}$ climate chamber. Unpolluted soil was collected from the farmland of Chengdu Campus of Sichuan Agricultural University.

Experimental Design. The experiment was conducted in Chengdu Campus of Sichuan Agricultural University from April to May 2018. In March 2018, the unpolluted soil was air-dried and passed through a $5-\mathrm{mm}$ sieve. $3 \mathrm{~kg}$ air-dried soil was weighed into each plastic pot $(15 \mathrm{~cm}$ high, $18 \mathrm{~cm}$ in diameter), soaking uniformly $\mathrm{Na}_{2} \mathrm{SeO}_{3}$ by $0,5,10,25,50,75$ and $100 \mathrm{mg} / \mathrm{kg}$ respectively and balanced for 4 weeks. In April 2018, the same growing S. alatum with two real leaves were transplanted into the pots. Four $S$. alatum were planted in each pot. Five replicates per treatment and all pots were watered each day to keep the soil moisture about $80 \%$. The distance between pots was $15 \mathrm{~cm}$, and the pot position exchanged aperiodically to weaken the impact of the marginal effects. After 40 days, the upper mature leaves of $S$. alatum were collected to determine the photosynthetic pigment (chlorophyll a, chlorophyll $\mathrm{b}$ and carotenoid) contents [10].

Statistical Analyses. Statistical analyses were conducted using statistical software of SPSS 17.0. Data were analyzed by one-way ANOVA with least significant difference at $5 \%$ confidence level.

\section{Results and Discussion}

Chlorophyll a content in $S$. alatum. For the content of chlorophyll a, except the Se concentration of $10 \mathrm{mg} / \mathrm{kg}$ had no significant effect on the chlorophyll a content of $S$. alatum, other Se concentrations all significantly reduced the chlorophyll a content of S. alatum (Figure 1). And when the Se concentration started at $10 \mathrm{mg} / \mathrm{kg}$, the content of $S$. alatum chlorophyll a decreased with increasing Se concentration. In all treatments, the Se concentration of $100 \mathrm{mg} / \mathrm{kg}$ resulted in the lowest chlorophyll a content of the $S$. alatum $(P<0.05)$.

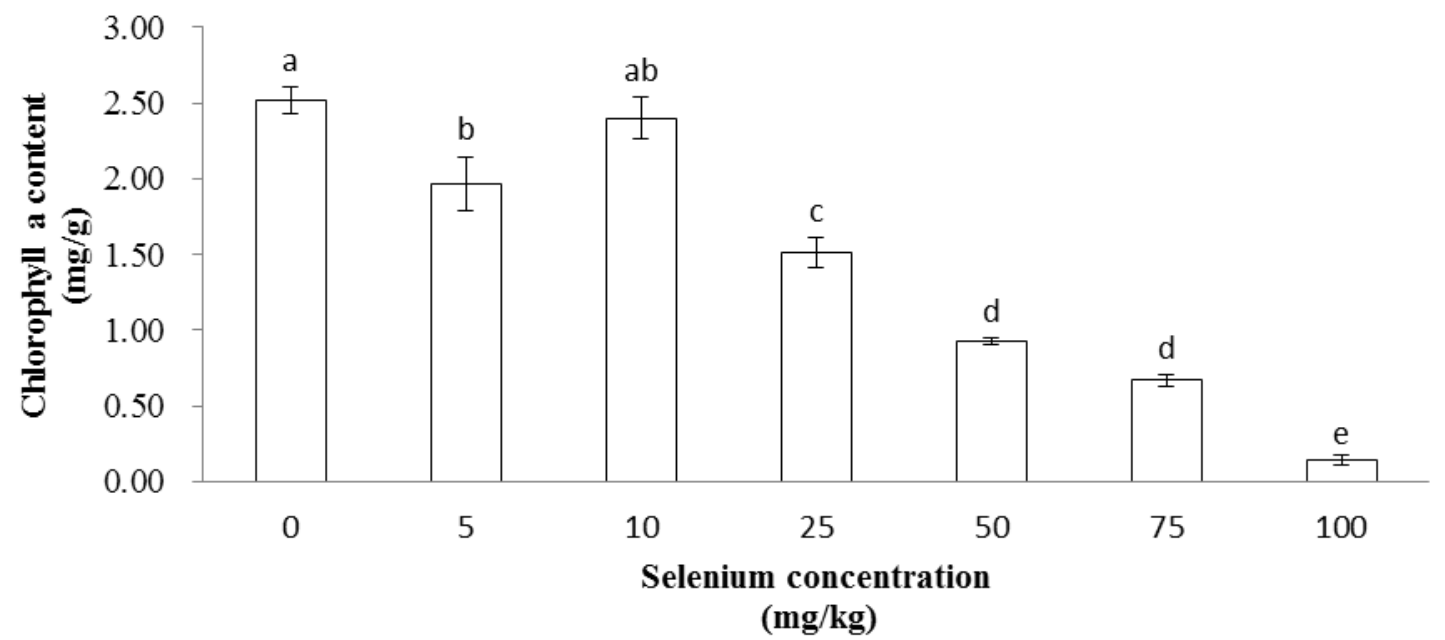

Figure 1 Chlorophyll a content in $S$. alatum

Means with the same letter within each column are not significantly different at $p<0.05$.

Chlorophyll b content in $S$. alatum. For the content of chlorophyll b, except the Se concentration of $10 \mathrm{mg} / \mathrm{kg}$ had no significant effect on the chlorophyll b content of $S$. alatum, other Se concentrations all significantly reduced the chlorophyll b content of $S$. alatum (Figure 2). And when the Se concentration started at $10 \mathrm{mg} / \mathrm{kg}$, the content of $S$. alatum chlorophyll b decreased with increasing Se concentration. In all treatments, the Se concentration of $100 \mathrm{mg} / \mathrm{kg}$ resulted in the lowest chlorophyll b content of the $S$. alatum $(P<0.05)$.

Carotenoid content in $S$. alatum. For the content of carotenoid, except the Se concentration of $10 \mathrm{mg} / \mathrm{kg}$ had no significant effect on the carotenoid content of $S$. alatum, other Se concentrations all significantly reduced the carotenoid content of $S$. alatum (Figure 3 ). The Se concentrations order of $S$. alatum carotenoid content from large to small was ranked: $0 \mathrm{mg} / \mathrm{kg}, 10 \mathrm{mg} / \mathrm{kg}, 25 \mathrm{mg} / \mathrm{kg}, 5$ $\mathrm{mg} / \mathrm{kg}, 50 \mathrm{mg} / \mathrm{kg}, 75 \mathrm{mg} / \mathrm{kg}$ and $100 \mathrm{mg} / \mathrm{kg}$. Among all treatments, the Se concentration of 100 
$\mathrm{mg} / \mathrm{kg}$ resulted in the lowest carotenoid content of the $S$. alatum $(P<0.05)$.

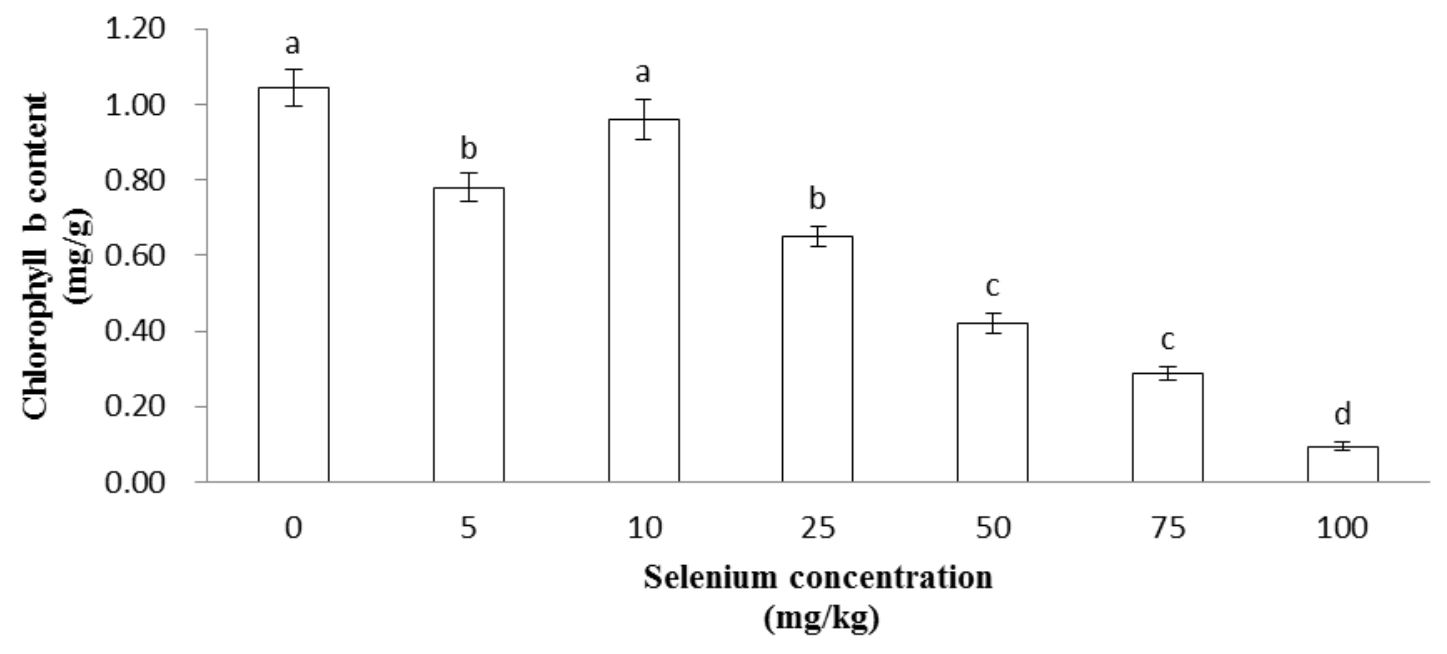

Figure 2 Chlorophyll b content in S. alatum

Means with the same letter within each column are not significantly different at $p<0.05$.

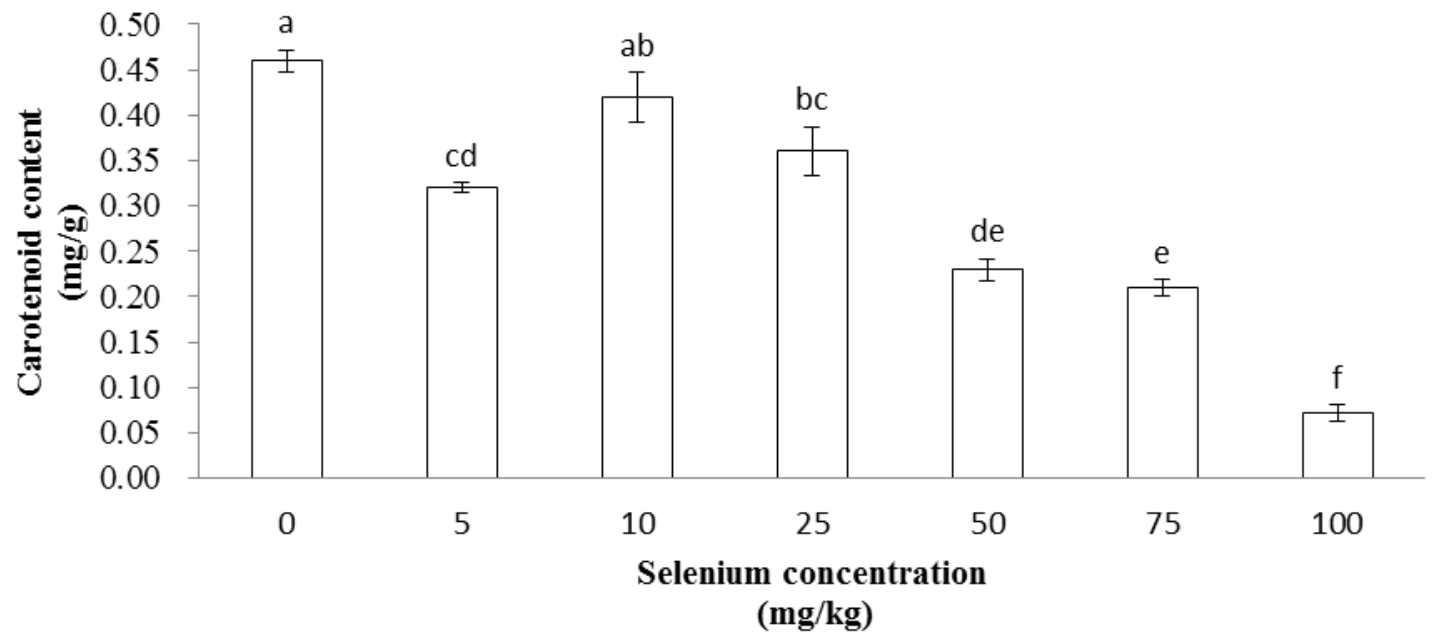

Figure 3 Carotenoid content in S. alatum

Means with the same letter within each column are not significantly different at $p<0.05$.

\section{Conclusions}

This study showed that different concentrations of selenium stress have different effects on the photosynthetic pigment contents of $S$. alatum. For $S$. alatum chlorophyll a and chlorophyll b contents, the selenium concentrations order of $S$. alatum chlorophyll a and chlorophyll b contents from large to small were both ranked: $0 \mathrm{mg} / \mathrm{kg}, 10 \mathrm{mg} / \mathrm{kg}, 5 \mathrm{mg} / \mathrm{kg}, 25 \mathrm{mg} / \mathrm{kg}, 50 \mathrm{mg} / \mathrm{kg}, 75 \mathrm{mg} / \mathrm{kg}$ and $100 \mathrm{mg} / \mathrm{kg}$. Compared with the $0 \mathrm{mg} / \mathrm{kg}$, only the selenium concentration of $10 \mathrm{mg} / \mathrm{kg}$ had little effect on the chlorophyll a, chlorophyll b and carotenoid contents of S. alatum, other Se concentrations all significantly reduced the photosynthetic pigment contents of $S$. alatum. These results indicated that high concentrations of selenium stress have a significant inhibitory effect on the photosynthetic pigment contents of $S$. alatum, which were not conducive to the growth of $S$. alatum. And only the concentration of $10 \mathrm{mg} / \mathrm{kg}$ of selenium had little effect on the photosynthetic pigment contents of $S$. alatum. Therefore, $S$. alatum could grow normally under selenium stress of $10 \mathrm{mg} / \mathrm{kg}$. 


\section{Acknowledgements}

This work was financially supported by the Application Infrastructure Project of Science and Technology Department of Sichuan Province (2016JY0258).

\section{References}

[1] F. Liu, Q. K. Zhou, S. B. Zhou, Y. J. Huang, K. Liu, D. D. Zhang and H. Zhou: Chinese Journal of Soil Science Vol. 47 (2016), P. 129.

[2] J. Zhao: Chinese Journal of Control of Endemic Diseases Vol. 19 (2004), p. 281.

[3] G. F. Shi, J. Zhang and H.J. Li: Studies of Trace Elements and Health Vol. 18 (2001), p. 51.

[4] F. W. Ávila, Y. Yang, V, Faquin, S. J. Ramos, L. R. G. Guilherme, T. W. Thannhauser and L. Li: Food Chemistry Vol. 165 (2014), p. 578.

[5] I. Rosenfeld and O. A. Beath: Selenium. Geobotany, biochemistry, toxicity, and nutrition (Academic Publications Press, NY 1964).

[6] T. F. Chen, W. J. Zheng, Y. Luo, F. Yang, Y. Bai and F. Tu: Journal of Plant Physiology and Molecular Biology Vol. 31 (2005), p. 369.

[7] H. X. Lv, C. Y. Tian, Z. Y. Wang and K. Zhang: Arid Land Geography Vol. 38 (2015), p. 83.

[8] T. S. Xiarepati and T. E. D. Alimu: Guangdong Chemical Industry Vol. 44 (2017), p. 76.

[9] X. C. Zeng, Y. Z. Xu, X. Q. Wang and F. Q. Zhang: Journal of Shenyang Agricultural University Vol. 39 (2008), p. 240.

[10]Z. B. Hao, J. Chang and Z. Xu: Plant Physiology Experiment (Harbin Institute of Technology Press, China 2004). 